\title{
Developmental Biology of the Pancreas
}

\author{
Pedro Luis Herrera Merino* \\ Department of Morphology, University of Geneva Medical School, Geneva, Switzerland
}

\begin{abstract}
In this review, I summarize some aspects of murine pancreas development, with particular emphasis on the analysis of the ontogenetic relationships between different pancreatic cell types. Lineage analyses allow the identification of the progenitor cells from which mature cell types arise. The identification and successful in vitro culture of putative pancreatic stem cells is highly relevant for future cell replacement therapies in diabetic patients.
\end{abstract}

Index Entries: Pancreas; islet; mouse; transgenic; development; cell lineage; stem cell; cre/loxP; diabetes; insulin; diphtheria toxin.

\section{INTRODUCTION}

The selective ablation of specific cell types in transgenic mice through the expression of toxin genes is a useful approach in cell lineage experiments in vivo (1-4). By means of the glucagon promoter-driven expression of a diphtheria toxin (DT) A gene, we demonstrated that glucagon cells are not precursors of insulinproducing cells (3). We pursued these analyses by labeling progenitor cells through the expression of Cre recombinase in doubly transgenic mice (5). With this approach, we, and subsequently others, have been able to show that all

\footnotetext{
*Author to whom all correspondence and reprint requests should be addressed. E-mail: Pedro.Herrera@ medecine.unige.ch.
}

pancreatic cells differentiate from $p d x 1$ expressing precursors (unpublished observations and (5-7)). Similarly, $p 48$ activity is found in precursors of both exocrine and endocrine pancreatic cell lineages (8). We have also shown that islet endocrine cells derive from progenitor cells that express ngn3 and pax6 genes almost concomitantly (unpublished observations and (7)), and that insulin cells do not derive from glucagon-expressing progenitors, nor glucagon cells from insulin progenitors (5).

\section{PANCREAS DEVELOPMENT}

The pancreas is a mixed gland. The exocrine pancreas represents the majority of the tissular mass and is composed of secretory acini and excretory ducts. Clusters of cells, the islets of 
Langerhans, are embedded in the exocrine tissue and form the endocrine pancreas. Islets are composed of four cell types: $\beta$-cells that produce insulin, and $\alpha_{-}, \sigma_{-}$, and PP cells that produce glucagon, somatostatin, and pancreatic polypeptide, respectively.

\section{Organogenesis From Several Pancreatic Buds}

The pancreas initially develops from distinct dorsal and ventral primordia brought together to form the single mature organ. This involves a cascade of inductions associated with the expression of particular transcription factors. Pancreatic buds evaginate from the early foregut endoderm caudal to the stomach primordium, near the prospective liver; the molecular determinants that define the position of the pancreas along the anterior-posterior axis remain unknown $(9,10)$. The first hormone-containing cells found in early primordia appear located exclusively within the epithelia of the embryonic ducts or cords $(11,12)$. Because these cells often simultaneously express more than one hormone (12-14), the existence of a common, glucagon-expressing precursor cell for all four islet cell types was proposed (15).

Commitment to a pancreatic fate occurs as early as embryonic d 8-8.5 (E8-E8.5) in mice. Permissive signals released from adjacent mesodermal structures, including the notochord, aorta, and cardiac mesoderm, are important for induction of the pancreatic program. The notochord induces dorsal pancreas development through the inhibition of Shh (Sonic hedgehog) expression in prepancreatic dorsal endoderm. Shh is expressed in the early gut endoderm and aids in its development (9,16-18). This Shh repression, which appears to be mediated by activin $\beta B$ and Fibroblast growth factor-2 (FGF2) (19), is permissive for the expression of $P d x 1$. Shh is also repressed, and $P d x 1$ expressed, in the ventral prepancreatic endoderm.

It is intriguing that the same mesenchymal morphogens have opposite inductive effects on the dorsal and ventral pancreas; in the absence of dorsal mesoderm, the dorsal endoderm expresses liver markers, whereas without ventral mesoderm (i.e., without cardiac mesoderm and septum transversum), the ventral endoderm "defaults" to pancreas formation instead of liver. Indeed, signals from ventral mesoderm (FGFs) promote hepatic development (20).

The first indication of morphogenesis occurs at E9.5, when the dorsal mesenchyme condenses and the underlying endoderm evaginates to form a recognizable dorsal pancreatic bud; the ventral bud appears $1 \mathrm{~d}$ later (E10.5). Both buds, stimulated by mesenchymal signals, subsequently proliferate and form multiple branches, which ultimately fuse together by day E14 (the ventral bud translocates toward the dorsal during gut rotation).

\section{Timing of Appearance of Differentiated Endocrine Phenotypes}

In mice, the first identifiable differentiated cells are glucagon-producing cells. These cells are detectable already at E9.5 in the dorsal pancreatic bud and $1 \mathrm{~d}$ later in the ventral, whereas the first insulin-producing cells are present the following day (E10.5-E11) in both primordia. After branching, at E13.5, somatostatin-positive cells are detectable in both buds, and the exocrine pancreas containing well-formed acini begins to differentiate at E14.5. Three days before birth, at E16.5, PP-secreting cells are also detected (unpublished observations) and the first islets of Langerhans are formed at E18.5 (12).

We determined the timing of hormone gene expression by reverse transcriptase-polymerase chain reactions of total RNAs extracted from pancreatic buds and surrounding tissues at different developmental stages $(12,21)$. Glucagon and somatostatin mRNAs are found very early (E8.5-E9), probably from extrapancreatic sources; insulin I transcript was detected in E10.5 buds, whereas insulin II was found only $1 \mathrm{~d}$ later. Surprisingly, PP mRNA is detected from E10.5 onward, thus indicating PP gene expression early in the developing mouse pancreas. 

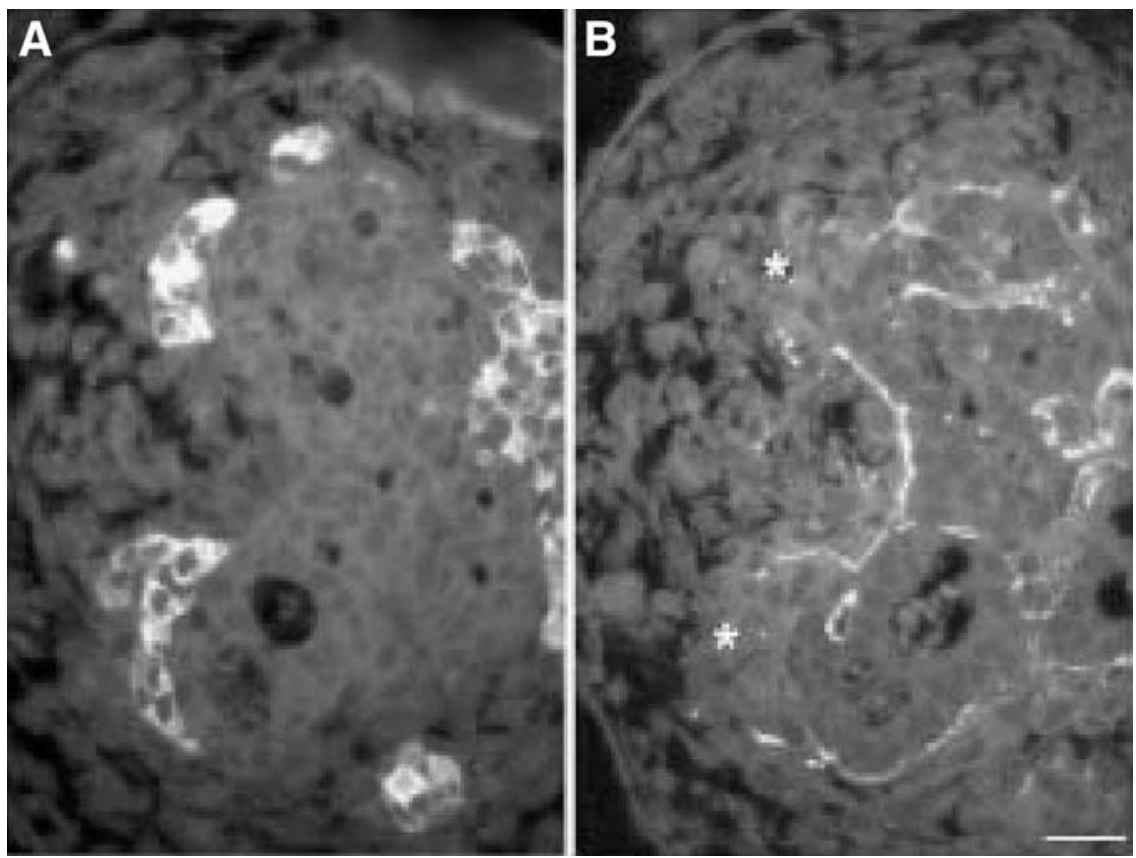

Fig. 1. Immunohistochemical analysis of pancreatic buds cultured in collagen gels. Two consecutive semithin sections of an E12.5 pancreatic bud cultured for $7 \mathrm{~d}$ were stained with two different antibodies: antiglucagon (A) and anticollagen IV (B). Clusters of endocrine cells stained with antiglucagon antibody (A) migrate from the ductlike cords of epithelial cells into the surrounding mesenchyme. This process involves interactions between endocrine cells and the extracellular matrix (ECM), through adhesion molecules, and active proteolysis of the ECM, as illustrated with the anticollagen IV staining (B). Collagen IV is a main component of epithelial basement membranes. Digestion of collagen IV is shown to occur at places were endocrine clusters of cells are budding (asterisks in panel (B)). Scale bar is $20 \mu \mathrm{m}$.

\section{Islet Formation}

Analysis of endocrine cells in situ suggests three major patterns of endocrine cell localization in embryonic pancreas. The earliest hormone-containing cells are individual cells located within the epithelium of pancreatic ducts. In both dorsal and ventral buds, the majority of these endocrine cells contain more than one hormone costored within the same secretory granules (12). Subsequently, these cells migrate into the surrounding interstitia, forming clusters of irregular shape and size that become vascularized quickly. This process involves interactions between cells through adhesion molecules and active proteolysis of the extracellular matrix $(9,22)$. For instance, collagen IV, which is a component of basement membranes, is absent at the places where these first endocrine cells appear (Fig. 1; unpublished observations). Finally, starting on E18.5, as indicated previously, typical islets are formed with centrally located $\beta$-cells and with the adult "one cell-one hormone" phenotype (12).

\section{TRACKING CELL FATES IN THE PANCREAS: HISTORICAL SYNOPSIS}

Development of metazoan organisms from one-celled embryos requires that cells progressively become highly specialized to fulfill 
Table 1

Overview of the Methods Used to Trace Cell Lineages

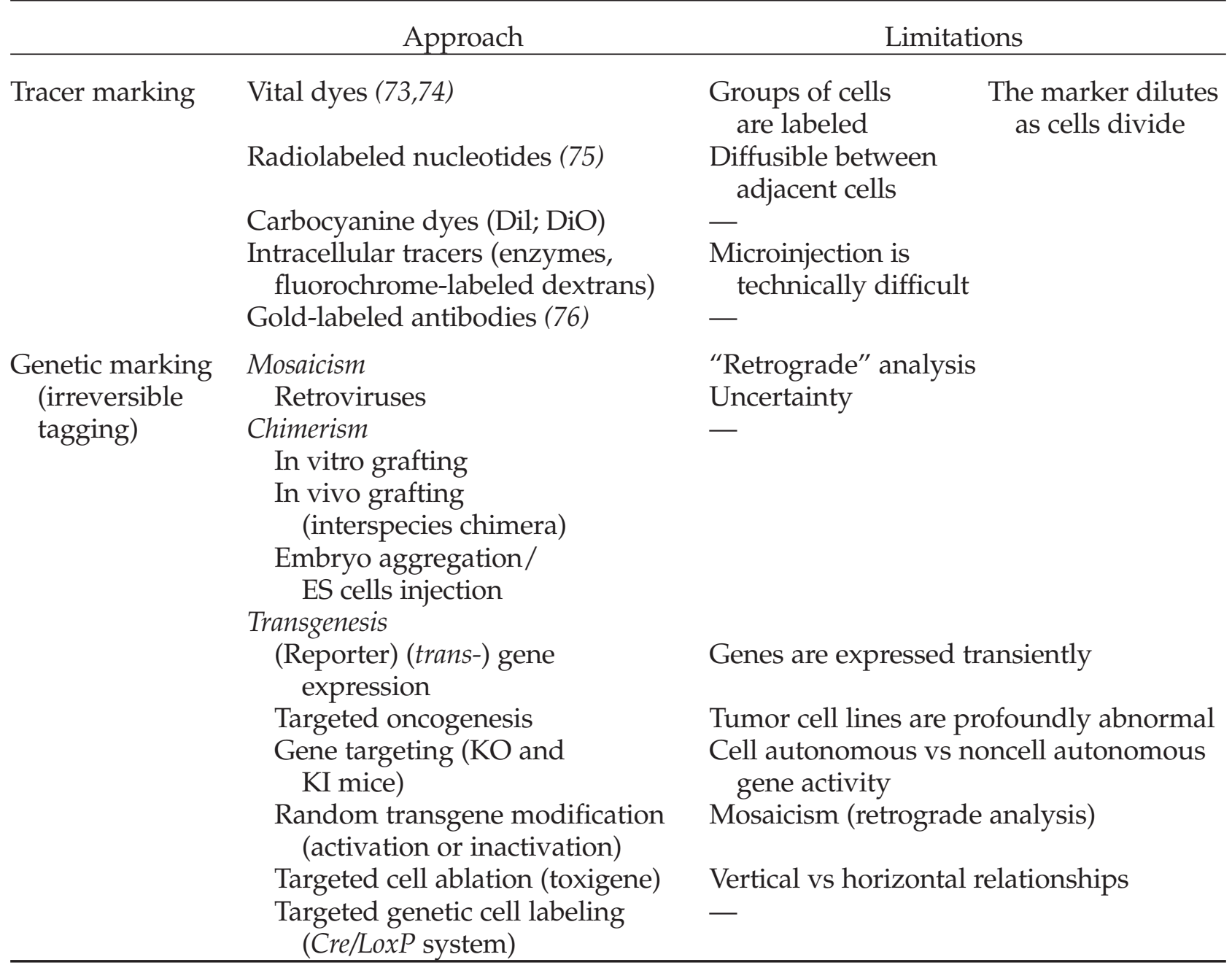

particular tasks; interactions between neighbor cells determine their respective destiny. Understanding these developmental processes implies knowledge of the precise lineages of cells, and the observer requires a method to reliably identify particular cells and all of their progeny to reveal their fates.

To follow cells over long periods and through complex differentiation programs, irreversible (genetic) tagging is required. Three different cell-lineage tracing techniques are summarized in Table 1.

\section{Generation of Mosaics}

Embryos can be marked through infection with replication-deficient retroviruses bearing a gene encoding a marker (such as $\beta$-galactosidase, alkaline phosphatase, or green fluorescent protein [GFP]) (23-26). The approach consists in using a low viral titer so that infection is a rare event; therefore, marked cells in a given infected embryo are assumed to be clonally related. Infected embryos are thus mosaics of marked and unmarked cells. The main dis- 
advantage of this approach, apart from the uncertainty regarding the interpretation of the results, is that labeled cells are not chosen directly; this lineage analysis is thus "retrospective." Using this method with pancreatic rudiments cultured in vitro, Fishman and Melton demonstrated that a single infected pancreatic progenitor cell is able to give rise to both exocrine and endocrine cells (25).

\section{Generation of Chimeras}

Another way to circumvent the problem of dilution of tracer dyes was devised in the 1920s through the generation of interspecies chimeras by transplantation (grafting) or, much later, by aggregating two mouse embryos. Chimeras are derived from more than one embryo; therefore, their bodies are formed of cells from different individuals having different genetic constitutions. In transplantation chimeras, donor and host cells can be easily distinguished by morphological differences (27-31). With this method (grafting quail neural crest cells on chick embryos), Le Douarin demonstrated that neural crest cells do not contribute to the formation of pancreatic endocrine cells (30).

In vitro grafting (i.e., tissue cocultures of rudiments from different embryos) is another variation of the chimera approach. With this system, Percival and Slack (32) showed that the pancreatic mesenchyme does not contribute to pancreatic cells; when labeled prepancreatic endoderm was cultured with unmarked mesenchyme, only the endoderm gave rise to acini, ducts, and islets.

Mouse aggregation chimaeras, using, for instance, transgenic and wild-type morulae, or chimeras generated by injection of pluripotent ES cells into host blastocysts, are powerful tools to identify different cell populations within a single organ in vivo. With the embryo aggregation approach, Jami and coworkers demonstrated that pancreatic islets of Langerhans are of polyclonal origin (i.e., that endocrine cells within a particular islet derive from different progenitors) (33).

\section{Generation of Transgenics}

Two sophisticated methods, using transgenic mice, have been introduced more recently, and both were first employed by our laboratory to trace pancreatic cell lineages $(3,5)$. The first is based on targeted ablations of given cell types by means of cell type-specific promoters to express toxin genes. The rationale is that missing cells are derived from, or dependent on, the cell type destroyed, which would then be a putative precursor or adjuvant cell. A refinement of this approach was successfully used to address the enteroendocrine cell lineages through the conditional ablation of secretin cells, on administration of ganciclovir, in transgenic mice expressing herpes simplex virus 1 thymidine kinase under the control of a secretin promoter (4). The viral enzyme herpes simplex virus 1 thymidine kinase phosphorylates the thymidine analog ganciclovir, which renders it mutagenic and cytotoxic.

The second approach is the irreversible targeted tagging (labeling) of a given cell type using a promoter to express Cre recombinase (Cre/LoxP system) $(34,35)$. This is the most reliable and powerful method to trace cell lineages in Amniota in vivo; it permits detection of descendants that no longer express the gene of interest (Fig. 2).

Both approaches were pioneered in pancreatic rudiment cell lineage tracing, and are discussed in more detail in the following sections $(3,5)$. I now summarize some knockout experiments that have demonstrated a crucial role for a few genes in pancreas development.

\section{CELL VS NONCELL AUTONOMOUS EXPRESSION OF GENES}

Inactivation of genes (gene targeting or ablation) in knockout (KO) mice is one way to study their function. This may result in loss of some particular cell type(s) or activation of reporter gene expression (knock-in mice). Although these results have been considered by some workers as a means to identify precursor cells, 
A
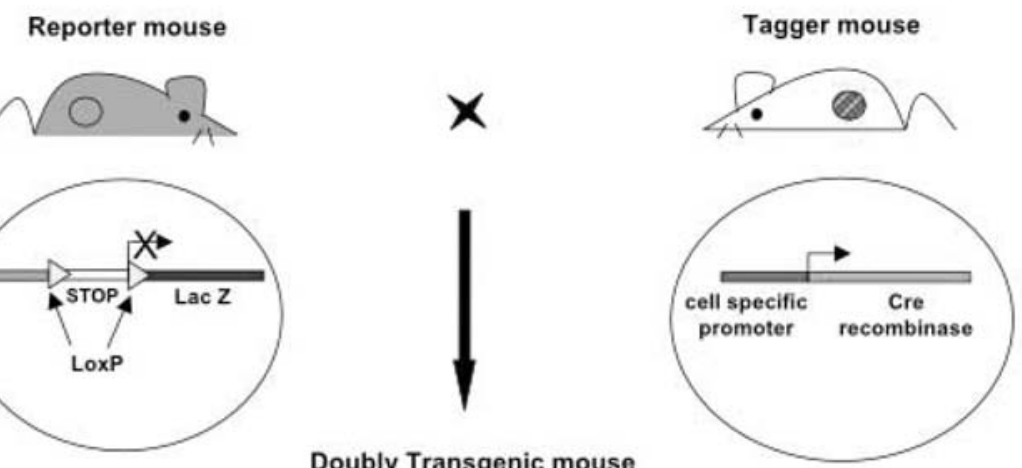

Doubly Transgenic mouse
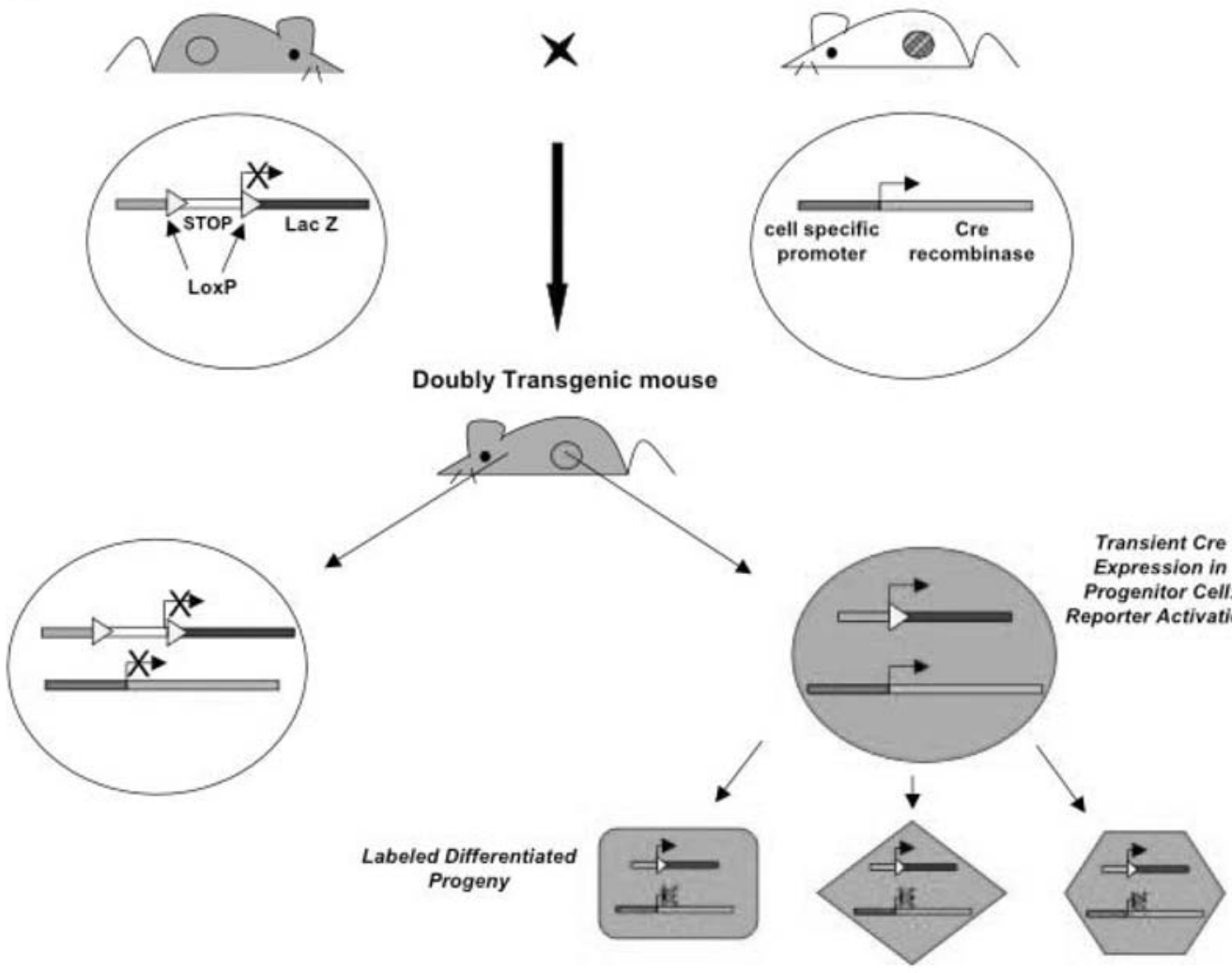

B

Reporter Mouse

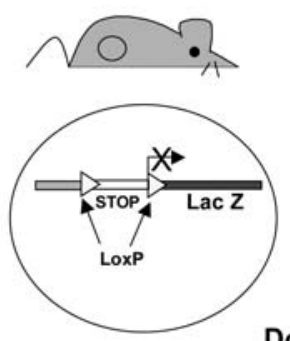

Doubly Transgenic Mouse
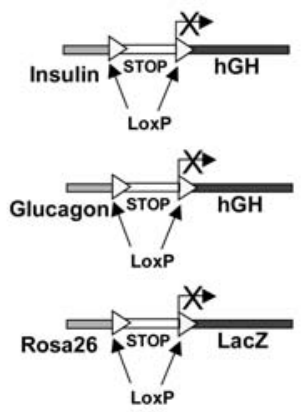

Tagger Mouse

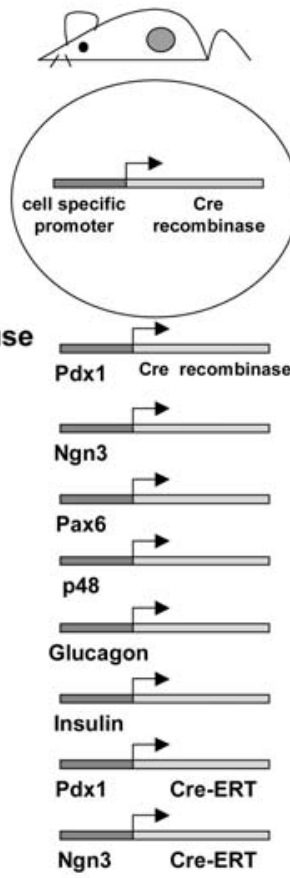


Fig. 2. Tracing cell lineages with the Cre/LoxP strategy. (A) To genetically label pancreatic progenitor cells, two different strains of transgenic mice are needed. The "reporter mouse" bears a reporter transgene (in the cartoon the $\beta$-galactosidase coding region) placed under the control of a promoter (either tissue-specific or ubiquitous) and downstream of a LoxP-flanked transcription termination cassette (STOP sequence). The "tagger" mouse ("marker" or "deletor" mouse) has a transgene encoding the Cre recombinase gene under the control of a cell-specific promoter, such as would be active in putative pancreatic progenitor cells. In doubly transgenic mice, the expression of the tagger transgene in a precursor cell results in the excision of the reporter's STOP sequence, thus allowing its expression ( $\beta$-galactosidase). This tag is then genetically transmitted to all the progeny of this cell and permits the tracing of its lineage during the formation of the pancreas. In (B), the transgenes described in the text are shown.

this is conceptually wrong. Genes are often expressed transiently, and cytodifferentiation during development is based on differential gene expression. Moreover, many genes act non-cell autonomously (i.e., in paracrine ways). As a consequence, cell ablation resulting from null mutations ( $\mathrm{KO}$ mice) cannot be taken as evidence of cell lineage relationships among different cell types. Strictly, the gene KO experiments tell us whether a given gene is necessary for a given cell type to differentiate.

Mesenchymal factors are non-cell autonomous inducers of epithelial (endodermal) cell differentiation. Epithelial-mesenchymal interactions are essential for pancreas morphogenesis and cytodifferentiation. Different pancreatic lineages require different mesenchymal factors for their development. For instance, when the pancreatic bud epithelium is cultured in the absence of mesenchyme, or grafted under the renal capsule, only endocrine cells differentiate (36). The identity of most soluble mesenchymal factors remains unclear, but the transforming growth factor (TGF)- $\beta$, FGF, and epidermal growth factor (EGF) signaling pathways appear to be involved $(9,16,37)$. The TGF$\beta$ superfamily accessory binding protein follistatin, which is expressed in pancreatic mesenchyme, promotes exocrine differentiation (22), whereas treatment with TGF- $\beta 1$ has the opposite effect (38-41).

Targeted disruption of Isl1 (ISLET1, a LIM homeodomain protein), which is expressed in early endocrine cells, abolishes endocrine differentiation (Table 2). Isl1 is nevertheless first expressed in the mesenchyme surrounding the dorsal primordium. In Isl1-/- embryos there is no dorsal pancreatic bud, and this is a consequence of the lack of dorsal mesenchyme (42).

Inactivation of the adhesion molecule $\mathrm{N}$-cadherin also results in agenesis of the dorsal pancreas, which is associated again with a loss of dorsal mesenchyme (43). Interestingly, in these animals the Isll expression persists in the mesenchyme and in prospective dorsal pancreatic epithelium, whereas dorsal $P d x-1$ expression is normal by $\mathrm{E} 9$ but is then rapidly restricted to the prospective ventral pancreas. Because $P d x-1$ is similarly dorsally downregulated in Isl1-/mice (42), it appears that the dorsal mesenchyme is necessary to maintain $P d x-1$ expression. In vitro recombination experiments demonstrate that wild-type mesenchyme rescues morphogenesis and cytodifferentiation in $N$-cadherin-/- dorsal endoderm.

\section{Transcription Factors in Pancreas Development}

Even though transcription factors are likely to act cell autonomously, the consequences of their activity indirectly affect neighbor cells in a paracrine (non-cell autonomous) way. Many transcription factors, mostly homeobox genes, have been mapped to specific regions of the endoderm, and to the surrounding visceral 
Table 2

Some Factors Involved in Pancreas Development, as Determined Using KO Mice

\begin{tabular}{|c|c|c|c|}
\hline Targeted Gene & Dorsal Pancreas & Ventral Pancreas & Ref. \\
\hline$P d x 1$ & \multicolumn{2}{|c|}{ Aplasia } & $(45,46,67)$ \\
\hline Ngn3 & \multicolumn{2}{|c|}{ No islets } & (49) \\
\hline PTF1-p48 & \multicolumn{2}{|c|}{ No exocrine celss } & $(48)$ \\
\hline $\operatorname{Pax} 4$ & \multicolumn{2}{|c|}{ No $\beta$ - nor $\delta$-cells } & (53) \\
\hline Pax 6 & \multicolumn{2}{|c|}{ No $\alpha$-cells; Endocrine hypoplasia } & $(52)$ \\
\hline Isl1 & Agenesis; no mesenchyme & No endocrine cells & $(42)$ \\
\hline$H l x b 9$ & Agenesis & Fewer $\beta$-cells & $(68 ; 69)$ \\
\hline Hes1 & \multicolumn{2}{|c|}{ Hypoplasia } & (54) \\
\hline$N$-cadherin & Agenesis; no mesenchyme & Normal & (43) \\
\hline Beta2/NeuroD & \multicolumn{2}{|c|}{ Fewer $\beta$-cells; distorted islets } & $(70)$ \\
\hline Hnf6 & \multicolumn{2}{|c|}{ Endocrine hypoplasia } & $(71)$ \\
\hline$P b x 1$ & \multicolumn{2}{|c|}{ Hypoplasia } & (16) \\
\hline$N k x 2.2$ & \multicolumn{2}{|c|}{ Immature $\beta$-cells } & $(72)$ \\
\hline
\end{tabular}

mesenchyme, and are likely to modulate the mesoderm-endoderm interactions (44). Their involvement in pancreas determination, growth, and differentiation, has been assessed by their selective inactivation in mice (summarized in Table 2). Factors more relevant to pancreas development are briefly discussed herein.

PDX1 (pancreatic and duodenal homeobox1) is, together with the homeodomain protein HB9, the earliest marker of pancreatic bud cells, from E8.5. PDX1 is necessary for the development of the pancreas, because $P d x 1$-deficient mice have pancreatic aplasia $(45,46)$. However, insulin and glucagon cells are present in early embryonic buds of $P d x 1-/-$ mice, and their pancreatic mesenchyme develops normally. $P d x 1$ is not a "master control gene," because its ectopic expression in the hindgut endoderm is not sufficient to trigger pancreas formation (47).

The inactivation of two bHLH transcription factors, PTF1-p48 and Ngn3, suggest that they could be implicated in determining whether an early pancreas cell is to become exocrine or endocrine. Mice in which PTF1-p48 is inactivated have no exocrine pancreas $(8,48)$, whereas inactivation of $\mathrm{Ngn3}$ results in agenesis of endocrine pancreas (49). In pancreatic buds, NGN3 is detected in proliferating cells expressing PDX1, but not in hormone-containing cells. Overexpression of $\mathrm{Ngn3}$ (under the control of a $P d x 1$ promoter, in transgenic mouse embryos, or of a ubiquitous promoter, in electroporated chick embryos) is sufficient to drive differentiation of glucagon cells, but not of insulin cells $(44,50,51)$.

In the absence of the paired-box domain protein PAX6, known to be downstream of ISL1, and initially expressed in all pancreatic endocrine cells, the development of all endocrine lineages is affected (52). The PAX4 protein is specifically necessary for the production of mature $\beta$ and $\sigma$ cells (53). Interestingly, in Pax6-/- and Pax4-/- double mutants, islets are totally absent.

In summary, the gene inactivation studies show, among many other interesting findings, that (1) several mesenchymal factors, whether soluble factors, adhesion molecules, or transcription factors, are needed for pancreas development-by activating genes in the prospective pancreatic endoderm; (2) $P d x 1$ is necessary for growth of both pancreatic rudiments; (3) ptf1-p48 activity is required for exocrine pancreas differentiation; and (4) Ngn3, 
as well as Pax6 and Pax4, are necessary for the differentiation of islet endocrine cells.

Together, these results suggest that some gene products (ISL1, N-Cadherin, PDX1, p48, and NGN3), whose inactivation induces loss of differentiated cells, are candidate markers for pancreatic progenitor cells. The $\mathrm{KO}$ experiments also point to the principal role of the mesenchyme, whose absence inhibits pancreas formation, even though it has been reported not to directly contribute cells to the pancreas (32). This clearly illustrates that, even though extremely important, gene inactivation experiments cannot be interpreted as indicative of cell lineages when they result in cell loss. Therefore, we decided to genetically mark the cells expressing these candidate genes in transgenic mice to determine whether they give rise to the different adult pancreatic cell types.

\section{TRACING PANCREATIC CELL LINEAGES BY DELETING OR MARKING SPECIFIC CELL TYPES IN TRANSGENIC MICE}

\section{Ablation of Islet Cells by Targeted Expression of Hormone Promoter-Driven Toxigenes}

Until the Cre/LoxP system was developed in the mid-1990s, targeted cell ablation through the expression of toxin genes was the best approach to study the ontogenetic, or cell lineage, relationships between the different types of endocrine cells in islets. In a transient transgenic study, we generated embryos in which cells transcribing glucagon, insulin, or PP genes were destroyed by the promoter-targeted expression of DT A (3). If, as proposed by others, insulin cells were the descendants of glucagon-producing precursors, then the ablation of all glucagon-expressing cells would preclude the differentiation of insulin cells. On the contrary, we unambiguously demonstrated that glucagon expressing cells are not essential for the differentiation of $\beta$-cells, nor are insulin gene expressing cells essential for $\alpha$ cells. These experiments also indicated a close ontogenetic relationship between insulin, PP, and somatostatin cells, because DT A expression using a rat PP promoter resulted in concomitant loss of PP, insulin, and somatostatin cells. Whether this requirement of PP-expressing cells is through a cell lineage relationship or because such cells produce paracrine or endocrine factors necessary for the differentiation of insulin and somatostatin cells from undefined precursors remained undetermined with this approach.

\section{Islet Cell Lineage Analyses by Irreversibly Labeling Cell Progenitors}

Recent developments in gene recombination technology have allowed the irreversible "marking" of cells at one developmental stage using the promoter of a given active candidate marker gene, and therefore permit identification of all their descendants when the promoter is no longer active (Fig. 2).

In the context of our work, cells were genetically labeled that transcribe Pdx1, Ngn3, Pax6, glucagon, insulin, or PP genes early during development, and the analysis of islet $\alpha$ and $\beta$ cells, or the total pancreas, later in development or in the adult, to determine whether they are derived from these early Pdx1, Ngn3, Pax6, glucagon, insulin, or PP gene-expressing cells (5) (Fig. 3). To study the cell lineages of the endocrine pancreas we used a silent LoxPbearing reporter transgene that is "activated" in a tissue-specific manner through the activity of Cre recombinase made from a second tagger transgene (54).

The experimental design requires the generation of mice bearing two transgenes (summarized in Fig. 2). One transgene, the "reporter," is placed under the control of either tissue-specific (5) or ubiquitous promoters $(6-8,55-57)$ and contains the human growth hormone (5), $\beta$-galactosidase (58), human alkaline phosphatase $(6,56)$, or enhanced GFP (EGFP) (57) coding region placed downstream of a "floxed" (i.e., loxP-flanked) transcription termination site (STOP sequence) (59-61). Expression of the native reporter transgene 


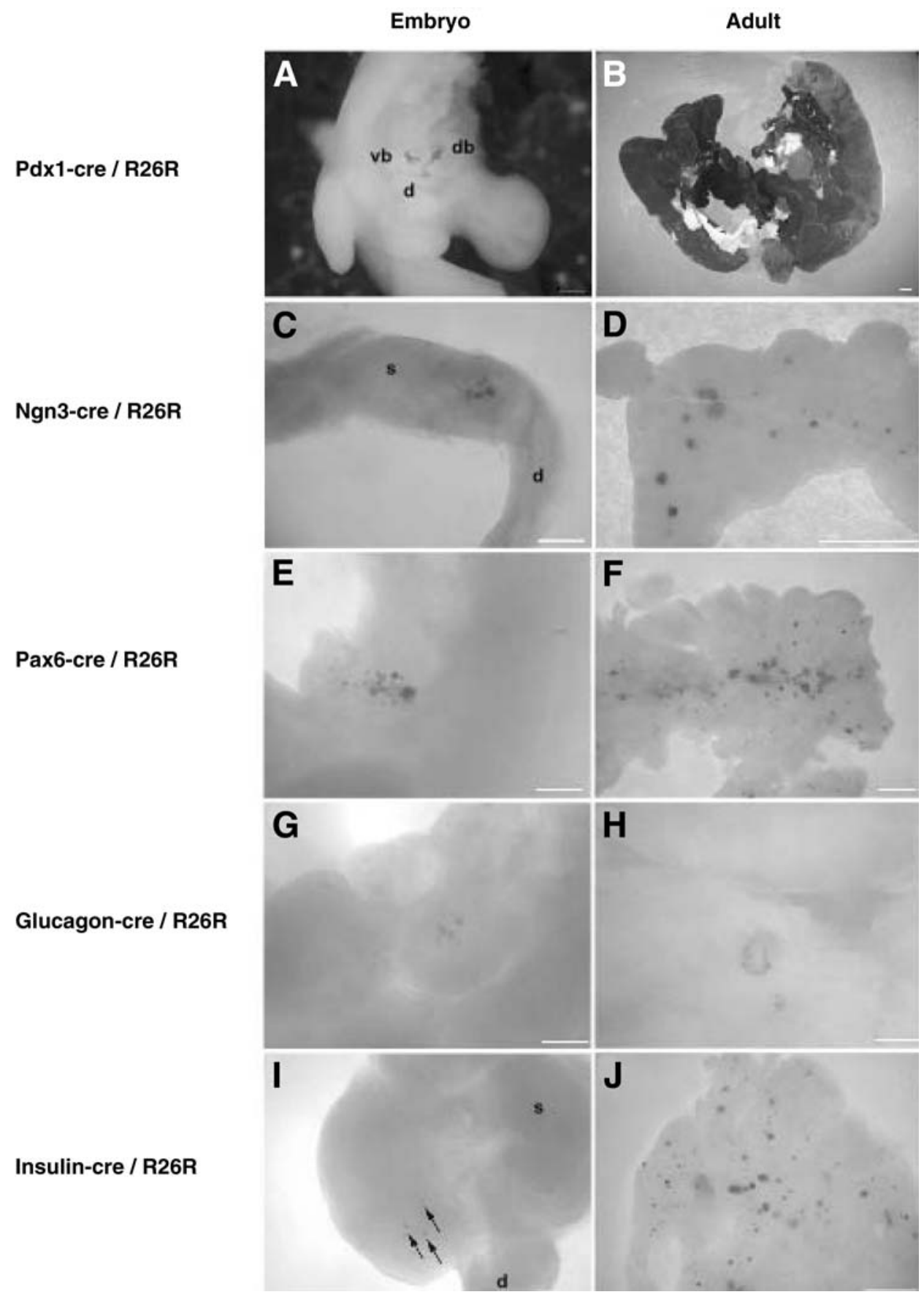

requires the deletion of this sequence, which is obtained in the presence of Cre recombinase.

The second transgene, the "tagger," consists of the Cre recombinase gene placed under the control of a promoter (transgenic or endogenous, as in knock-in mice) active in putative progenitor cells. Cre expression results in the irreversible deletion of the STOP (blocking) sequence of the reporter transgene, which is, in turn, activated, and thus labels all 
Fig. 3. Pancreatic cell lineage analyses. To study the cell lineages of pancreatic cells, we used, as reporter mice, strain R26R (55), and five different transgenic mice as taggers: (A, B) Pdx1-cre $(5,6)$, (C, D) Ngn3-cre (P.L.H., unpublished results), (E, F) Pax6-cre (66), (G, H) glucagon-cre (5), and (I, J) insulin-cre (5), among others. PDX1 is an early marker of pancreatic bud cells (E8.5) and is also found in the duodenal wall. In $P d x 1$-cre/R26R doubly transgenic embryos(A, B), $\beta$-galactosidase staining is found from E9.5 in the dorsal and ventral pancreatic buds and in the future duodenum (A) (an E11.5 embryo is shown). In adults, the entire pancreas and many duodenal cells are stained (B). These results demonstrate that $P d x 1+$ cells and their progeny participate in the formation of these two organs, and are pancreatic progenitor cells. NGN3 and PAX6 are shown to be essential for islet morphogenesis (Table 1), and are expressed early (from E9.5) in pancreatic development. In Ngn3-cre/R26R (C, D) and Pax6-cre/R26R (E, F) mice, $\beta$-galactosidase activity is shown in dorsal pancreatic buds-(C), E10.5, and (E), E11.5 - and in all endocrine cells forming the adult islets (D, F), demonstrating that NGN3+ and PAX6+ cells are endocrine progenitor cells. In glucagoncre/R26R $(G, H)$ and insulin-cre/R26R (I, J) mice, $\beta$-galactosidase staining is found in pancreatic buds at E11.5 and earlier (G, I) (E11.5 embryos are shown), and in $\alpha$ cells (H) and $\beta$-cells (J) in mature islets, respectively. (Note in panel (H) that only peripheral islet $\alpha$ cells are blue). All these results illustrate the power of the Cre/LoxP strategy to study cell lineages. $d$, duodenum; db, dorsal bud; s, stomach; vb, ventral bud. Scale bars are $0.25 \mathrm{~mm}$ in (A), (C), (E), (G), (H), and (I); $1 \mathrm{~mm}$ in (B), (D), (F), and (J).

progeny derived from those progenitors that originally expressed the tagger. Others have used this approach to analyze the life span of circulating memory $\mathrm{T}$ cells (59), but not to trace cell lineages.

Using lineage-specific expression of Cre recombinase, we first showed that islet $\alpha$ - and $\beta$-cell lineages appear to arise independently during ontogeny from a common $P d x 1$-expressing precursor (5) (Fig. 3A,B; Fig. 4). The cell ablation results (3) were thus confirmed and, in addition, it was discovered that the insulin cell lineage express the PP gene transiently (i.e., that insulin cells derive from $\mathrm{PP}+$ progenitors) and that glucagon cells, which do not express $P d x 1$, actually descend from PDX1+ progenitors. This observation, combined with the fact that glucagon cells are present in early pancreatic buds in Pdx1-/- embryos, is illustrative of the different nature of early (embryonic) and mature (islet) glucagon cells.

A newly available ubiquitous reporter mouse, R26R, made it possible to analyze all pancreatic cell lineages $(6,7,55)$. These studies confirmed that $P d x 1$ is expressed, at least transiently, in all pancreatic cell types $(6,7)$
(Fig. 3A,B), and that all islet endocrine cells derive from progenitors having transiently expressed Ngn3 (7) (Fig. 3C,D; Fig. 4).

The Cre-loxP system was initially devised to inactivate genes in selected tissues, rather than in the whole organism $(34,35)$. A subsequent refinement of this system allowed the exquisite temporal control of the recombinant activity of Cre in selected cells. One of these approaches consists of a fusion enzyme, Cre-ERT, in which the ligand-binding domain of a mutated estrogen receptor (ERT) that recognizes the antiestrogen tamoxifen (hydroxytamoxifen, 4-OHT), has been fused to Cre. In the absence of 4-OHT, CreERT remains in the cytoplasm. Administration of 4 -OHT results in its migration into the nucleus, as expected for a steroid hormone receptor-ligand complex. Accordingly, Cremediated recombination of genomic DNA is 4OHT-dependent in mice bearing a Cre-ERT transgene $(62,63)$. Because $4-\mathrm{OHT}$ is active for less than $48 \mathrm{~h}$ in mouse embryos, $\mathrm{Gu}$ and coworkers were able to pulse labeling Ngn3- or $P d x 1$-expressing cells during 1-2-d windows of development by using Ngn3-CreERT and $P d x 1-$ CreERT transgenes. The results with the latter 


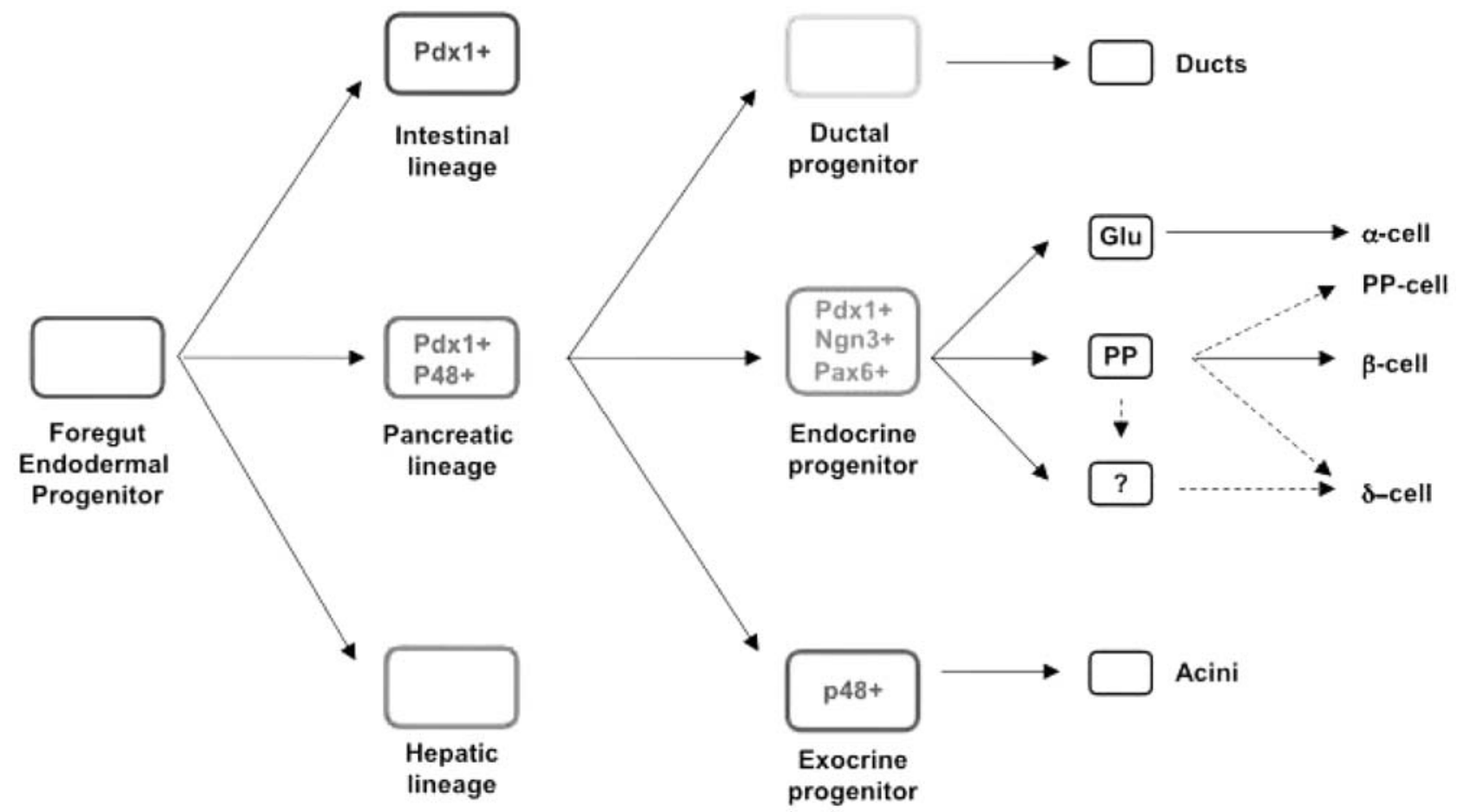

Fig. 4. Schematic representation of endodermal cell lineages as deduced from the Cre/LoxPmediated irreversible labeling of precursor cells. Liver, pancreas, and intestine derive from the same embryonic layer, the endoderm. Several reports show that $P d x 1$ and $p 48$ transcription factors are expressed in early presumptive pancreatic endodermal cells that are the progenitors of the entire pancreas (6-8). $p 48$ has been reported to be restricted later to the exocrine progenitor cells. Ngn3, which is expressed from E9.5 in early ducts or cords, is expressed in the progenitors of endocrine cells (7) (present report, Fig. 3C,D). Pax6, another transcription factor acting downstream of $P d x 1$, p48, and Ngn3, has also been shown to be expressed in endocrine progenitor cells (66) (present report, Fig. 3E,F). That glucagon-producing $\alpha$ cells represent an independent lineage was shown in two different reports $(3,5)$ (present report, Fig. $3 \mathrm{H}$, in which a glucagon-Cre transgene labels only $\alpha$ cells). Insulin-containing $\beta$-cells derive from PP-expressing progenitors, which are also required for the differentiation of somatostatin-containing $\sigma$-cells (3), either directly or noncell autonomously.

transgene were unexpected, for early labeling (at E8.5) marked only acinar and islet cells, but not ducts; indeed, duct cells were labeled only when 4-OHT was administered between E9.5 and E11.5. At E12.5, or later, only acini and islets were marked. This indicates that adult ducts develop from precursors expressing $P d x 1$ before E12.5 but after E8.5. In accordance with this interpretation, another elegant study in which pancreas development is modulated with doxycycline through activation or inacti- vation of $P d x 1$ activity, also points to a $P d x 1$ independent ductal development after this E12.5 stage (64). The presence of rare NGN3+ cells in the adult islet was also demonstrated in Ngn3-CreERT transgenics. Such cell population might contribute to the maintenance of the adult islet mass (7).

Ptf1-p48 inactivation suggested that this gene is required for exocrine pancreas development (48). To trace the lineage of Ptf1-p48-expressing cells, Kawaguchi et al. (8) placed the Cre recom- 
binase under the control of the endogenous Ptf1-p48 promoter in a knock-in experiment. Surprisingly, nearly all acinar, ductal, and insular cells expressed the ubiquitous reporter transgene in heterozygous Ptf1-p48-cre mice, indicating that Ptf1-p48 expression does not commit precursors to exocrine lineages, but to all pancreatic cell fates (Fig. 4). In homozygous animals, the phenotype was similar to that observed in Ptf1-p48-deficient mice (48), which suggested that in the absence of PTF1-p48, pancreatic cells may revert to an intestinal epithelial fate. In summary, this result indicates that Ptf1$p 48$, as with $P d x 1$, is expressed in the exocrine (acinar and ductal) and endocrine cell lineages of the pancreas and is silenced in endocrine and duct cells shortly after they are committed.

\section{CONCLUSIONS AND PROSPECTIVE}

Understanding pancreatic morphogenesis and cell differentiation has obvious clinical implications. The potential to form pancreatic endocrine tissue, whether from stem or differentiated cells, located in ducts or elsewhere in the pancreas (or even in extrapancreatic tissues), should not be restricted to the period of embryonic development. After experimental injury, whether surgical (e.g., partial pancreatectomy, duct ligation.) or chemical (e.g., streptozotocin or exendin- 4 treatment), the formation of new islets in adult rodents occurs to some extent. $\mathrm{Pdx} 1$ is expressed in pancreatic ductal cells during regeneration (65) and in early pancreatic buds during development (45). However, we still must determine whether differentiation of new islets in the adult recapitulates the events taking place during development. In this context, the power and elegance of the Cre/LoxPbased approach to track cell lineages is also applicable to the analysis of transgenic mice encoding Cre recombinase in different subsets of pancreatic cell types. Thus to address these challenging questions, the strains of mice that have been employed to determine cell lineage relationships during development, are now unique tools to address the cell lineage relation- ships during adult regeneration (neogenesis) as well as for the inactivation of specific genes in these same pancreatic cell lineages ("conditional" $\mathrm{KO}$ mice).

In conclusion, the Cre/LoxP lineage tracing approach allows a better characterization of progenitor cells not only of the pancreas, but also for any organ. Improvement of this fundamental knowledge (i.e., the understanding of our body's cell lineages) should, in the future, help to devise new sources of replacement tissues to treat degenerative diseases resulting from extensive cell death.

\section{ACKNOWLEDGMENTS}

I am grateful to Jean-Dominique Vassalli, Pierre Vassalli, Alessandra Delacour, Virginie Nepote, and Kerstin Johansson for carefully reading the manuscript. The author is supported by grants of the Juvenile Diabetes Research Foundation (no. 1-2001-575) and the Swiss National Science Foundation (no. 3161724.00).

\section{REFERENCES}

1 Breitman, M. L., Bryce, D. M., Giddens, E., Clapoff, S., Goring, D., Tsui, L. C., et al. (1989) Analysis of lens cell fate and eye morphogenesis in transgenic mice ablated for cells of the lens lineage. Development 106, 457-463.

2 Breitman, M. L., Rombola, H., Maxwell, I. H., Klintworth, G. K., and Bernstein, A. (1990) Genetic ablation in transgenic mice with an attenuated diphtheria toxin A gene. Mol. Cell. Biol. 10, 474-479.

3 Herrera, P. L., Huarte, J., Zufferey, R., Nichols, A., Mermillod, B., Philippe, J., et al. (1994) Ablation of islet endocrine cells by targeted expression of hormone- promoter-driven toxigenes. Proc. Natl. Acad. Sci. USA 91, 12999-13003.

4 Rindi, G., Ratineau, C., Ronco, A., Candusso, M. E., Tsai, M., and Leiter, A. B. (1999) Targeted ablation of secretin-producing cells in transgenic mice reveals a common differentiation pathway with multiple enteroendocrine cell lineages in the small intestine. Development 126, 4149-4156. 
5 Herrera, P. L. (2000) Adult insulin- and glucagon-producing cells differentiate from two independent cell lineages. Development 127, 2317-2322.

6 Gannon, M., Herrera, P. L., and Wright, C. V. (2000) Mosaic Cre-mediated recombination in pancreas using the $\mathrm{pdx}-1$ enhancer/promoter. Genesis 26, 143-144.

$7 \mathrm{Gu}$, G., Dubauskaite, J., and Melton, D. A. (2002) Direct evidence for the pancreatic lineage: NGN3+ cells are islet progenitors and are distinct from duct progenitors. Development 129, 2447-2457.

8 Kawaguchi, Y., Cooper, B., Gannon, M., Ray, M., MacDonald, R. J., and Wright, C. V. (2002) The role of the transcriptional regulator Ptf1a in converting intestinal to pancreatic progenitors. Nat. Genet. 32, 128-134.

9 Johansson, K. A. and Grapin-Botton, A. (2002) Development and diseases of the pancreas. Clin. Genet. 62, 14-23.

10 Kim, S. K. and Hebrok, M. (2001) Intercellular signals regulating pancreas development and function. Genes. Dev. 15, 111-127.

11 Pictet, R. L., Clark, W. R., Williams, R. H., and Rutter, W. J. (1972) An ultrastructural analysis of the developing embryonic pancreas. Dev. Biol. $29,436-467$.

12 Herrera, P. L., Huarte, J., Sanvito, F., Meda, P., Orci, L., and Vassalli, J. D. (1991) Embryogenesis of the murine endocrine pancreas; early expression of pancreatic polypeptide gene. Development 113, 1257-1265.

13 Teitelman, G., Alpert, S., Polak, J. M., Martinez, A., and Hanahan, D. (1993) Precursor cells of mouse endocrine pancreas coexpress insulin, glucagon and the neuronal proteins tyrosine hydroxylase and neuropeptide $Y$, but not pancreatic polypeptide. Development 118, 1031-1039.

14 Teitelman, G., Lee, J. K., and Alpert, S. (1987) Expression of cell type-specific markers during pancreatic development in the mouse: implications for pancreatic cell lineages. Cell. Tissue Res. 250, 435-439.

15 Alpert, S., Hanahan, D., and Teitelman, G. (1988) Hybrid insulin genes reveal a developmental lineage for pancreatic endocrine cells and imply a relationship with neurons. Cell 53, 295-308.

16 Kim, S. K., Selleri, L., Lee, J. S., Zhang, A. Y., Gu, X., Jacobs, Y., et al. (2002) Pbx1 inactivation disrupts pancreas development and in Ipf1-deficient mice promotes diabetes mellitus. Nat. Genet. 30, 430-435.
17 Hebrok, M., Kim, S. K., St Jacques, B., McMahon, A. P., and Melton, D. A. (2000) Regulation of pancreas development by hedgehog signaling. Development 127, 4905-4913.

18 Hebrok, M., Kim, S. K., and Melton, D. A. (1998) Notochord repression of endodermal Sonic hedgehog permits pancreas development. Genes. Dev. 12, 1705-1713.

19 Kim, S. K., Hebrok, M., Li, E., Oh, S. P., Schrewe, H., Harmon, E. B., et al. (2000) Activin receptor patterning of foregut organogenesis. Genes Dev. 14, 1866-1871.

20 Gualdi, R., Bossard, P., Zheng, M., Hamada, Y., Coleman, J. R., and Zaret, K. S. (1996) Hepatic specification of the gut endoderm in vitro: cell signaling and transcriptional control. Genes Dev. 10, 1670-1682.

21 Gittes, G. K. and Rutter, W. J. (1992) Onset of cell-specific gene expression in the developing mouse pancreas. Proc. Natl. Acad. Sci. U S A 89, 1128-1132.

22 Miralles, F., Battelino T., Czernichow, P., and Scharfmann, R. (1998) TGF-beta plays a key role in morphogenesis of the pancreatic islets of Langerhans by controlling the activity of the matrix metalloproteinase MMP-2. J. Cell. Biol. 143, 827-836.

23 Bagley, J., Aboody-Guterman, K., Breakefield, X., and Iacomini, J. (1998) Long-term expression of the gene encoding green fluorescent protein in murine hematopoietic cells using retroviral gene transfer. Transplantation 65, 1233-1240.

24 Cepko, C. L., Roberts, B. E., and Mulligan, R. C. (1984) Construction and applications of a highly transmissible murine retrovirus shuttle vector. Cell 37, 1053-1062.

25 Fishman, M. P. and Melton, D. A. (2002) Pancreatic lineage analysis using a retroviral vector in embryonic mice demonstrates a common progenitor for endocrine and exocrine cells. Int. J. Dev. Biol. 46, 201-207.

26 Sanes, J. R., Rubenstein, J. L., and Nicolas, J. F. (1986) Use of a recombinant retrovirus to study post-implantation cell lineage in mouse embryos. EMBO J. 5, 3133-3142.

27. Spemann, H. (1921) Die erzeugung tierischer chimaeren durch heteroplastiche transplantation zwischen triton cristatus und taeniatus. Roux Arch. EntwMech. Org. 48, 533-570.

28. Spemann, H. and Mangold, H. (1924) Über induktion von embryonalanlangen durch implantation artfremder organisatoren. Roux Arch. EntwMech. Org. 100, 599-638. 
29. Waddington, C. H. (1932) Experiments on the development of chick and duck embryos, cultivated in vitro. Phil. Trans. R. Soc. Lond. B. 221, 179-230.

30 Le Douarin, N. M. (1988) On the origin of pancreatic endocrine cells. Cell 53, 169-171.

31 Oshima, H., Rochat, A., Kedzia, C., Kobayashi, K., and Barrandon, Y. (2001) Morphogenesis and renewal of hair follicles from adult multipotent stem cells. Cell 104, 233-245.

32 Percival, A. C. and Slack, J. M. (1999) Analysis of pancreatic development using a cell lineage label. Exp. Cell. Res. 247, 123-132.

33 Deltour, L., Leduque, P., Paldi, A., Ripoche, M. A., Dubois, P., and Jami, J. (1991) Polyclonal origin of pancreatic islets in aggregation mouse chimaeras. Development 112, 1115-1121.

34 Rajewsky, K., Gu, H., Kuhn, R., Betz, U. A., Muller, W., Roes, J., et al. (1996) Conditional gene targeting. J. Clin. Invest. 98, 600-603.

35 Sauer, B. (1993) Manipulation of transgenes by site-specific recombination: use of Cre recombinase. Methods Enzymol. 225, 890-900.

36 Gittes, G. K., Galante, P. E., Hanahan, D., Rutter, W. J., and Debase, H. T. (1996) Lineage-specific morphogenesis in the developing pancreas: role of mesenchymal factors. Development 122, 439-447.

37 Miettinen, P. J., Huotari, M., Koivisto, T., Ustinov, J., Palgi, J., Rasilainen, S., et al. (2000) Impaired migration and delayed differentiation of pancreatic islet cells in mice lacking EGFreceptors. Development 127, 2617-2627.

38 Sanvito, F., Herrera, P. L., Huarte, J., Nichols, A., Montesano, R., Orci, L., et al. D. (1994) TGF-beta 1 influences the relative development of the exocrine and endocrine pancreas in vitro. Development 120, 3451-3462.

39 Sanvito, F., Nichols, A., Herrera, P. L., Huarte, J., Wohlwend, A., Vassalli, J. D., et al. (1995) TGFbeta 1 overexpression in murine pancreas induces chronic pancreatitis and, together with TNF-alpha, triggers insulin-dependent diabetes. Biochem. Biophys. Res. Commun. 217, 1279-1286.

40 Crisera, C. A., Maldonado, T. S., Kadison, A. S., Li, M., Alkasab, S. L., Longaker, M.T., et al. (2000) Transforming growth factor-beta 1 in the developing mouse pancreas: a potential regulator of exocrine differentiation. Differentiation 65, 255-259.

41 Bottinger, E. P., Jakubczak, J. L., Roberts, I. S., Mumy, M., Hemmati, P., Bagnall, K., et al. (1997)
Expression of a dominant-negative mutant TGF-beta type II receptor in transgenic mice reveals essential roles for TGF-beta in regulation of growth and differentiation in the exocrine pancreas. EMBO J. 16, 2621-2633.

42 Ahlgren, U., Pfaff, S. L., Jessell, T. M., Edlund, T., and Edlund, H. (1997) Independent requirement for ISL1 in formation of pancreatic mesenchyme and islet cells. Nature 385, 257-260.

43 Esni, F., Johansson, B. R., Radice, G. L., and Semb, H. (2001) Dorsal pancreas agenesis in Ncadherin-deficient mice. Dev. Biol. 238, 202-212.

44 Schwitzgebel, V. M. (2001) Programming of the pancreas. Mol. Cell. Endocrinol. 185, 99-108.

45 Jonsson, J., Carlsson, L., Edlund, T., and Edlund, H. (1994) Insulin-promoter-factor 1 is required for pancreas development in mice. Nature 371, 606-609.

46 Offield, M. F., Jetton, T. L., Labosky, P. A., Ray, M., Stein, R. W., Magnuson, M. A., et al. (1996) PDX-1 is required for pancreatic outgrowth and differentiation of the rostral duodenum. Development 122, 983-995.

47 Heller, R. S., Stoffers, D. A., Hussain, M. A., Miller, C. P., and Habener, J. F. (1998) Misexpression of the pancreatic homeodomain protein IDX-1 by the Hoxa- 4 promoter associated with agenesis of the cecum. Gastroenterology 115, 381-387.

48 Krapp, A., Knofler, M., Ledermann, B., Burki, K., Berney, C., Zoerkler, N., et al. (1998) The bHLH protein PTF1-p48 is essential for the formation of the exocrine and the correct spatial organization of the endocrine pancreas. Genes Dev. 12, 3752-3763.

49 Gradwohl, G., Dierich, A., LeMeur, M., and Guillemot, F. (2000) neurogenin3 is required for the development of the four endocrine cell lineages of the pancreas. Proc. Natl. Acad. Sci. U S A 97, 1607-1611.

50 Apelqvist, A., Li, H., Sommer, L., Beatus, P., Anderson, D. J., Honjo, T., et al. (1999) Notch signalling controls pancreatic cell differentiation. Nature 400, 877-881.

51 Grapin-Botton, A., Majithia, A. R., and Melton, D. A. (2001) Key events of pancreas formation are triggered in gut endoderm by ectopic expression of pancreatic regulatory genes. Genes Dev. 15, 444-454.

52 St-Onge, L., Sosa-Pineda, B., Chowdhury, K., Mansouri, A., and Gruss, P. (1997) Pax6 is required for differentiation of glucagon-producing alpha-cells in mouse pancreas. Nature 387, 406-409. 
53 Sosa-Pineda, B., Chowdhury, K., Torres, M., Oliver, G., and Gruss, P. (1997) The Pax4 gene is essential for differentiation of insulin-producing beta cells in the mammalian pancreas. Nature 386, 399-402.

54 Jensen, J., Pedersen, E. E., Galante, P., Hald, J., Heller, R. S., Ishibashi, M., et al. (2000) Control of endodermal endocrine development by Hes1. Nat. Genet. 24, 36-44.

55 Soriano, P. (1999) Generalized lacZ expression with the ROSA26 Cre reporter strain. Nat. Genet. 21, 70-71.

56 Lobe, C. G., Koop, K. E., Kreppner, W., Lomeli, H., Gertsenstein, M., and Nagy, A. (1999) Z/AP, a double reporter for cre-mediated recombination. Dev. Biol. 208, 281-292.

57 Mao, X., Fujiwara, Y., Chapdelaine, A., Yang, H., and Orkin, S. H. (2001) Activation of EGFP expression by Cre-mediated excision in a new ROSA26 reporter mouse strain. Blood 97, 324-326.

58 Mao, X., Fujiwara, Y., and Orkin, S. H. (1999) Improved reporter strain for monitoring Cre recombinase-mediated DNA excisions in mice. Proc. Natl. Acad. Sci. U S A 96, 5037-5042.

59 Jacob, J. and Baltimore, D. (1999) Modelling Tcell memory by genetic marking of memory $\mathrm{T}$ cells in vivo [see comments]. Nature 399, 593-597.

60 Brocard, J., Warot, X., Wendling, O., Messaddeq, N., Vonesch, J. L., Chambon, P., et al. (1997) Spatio-temporally controlled site-specific somatic mutagenesis in the mouse. Proc. Natl. Acad. Sci. U S A 94, 14559-14563.

61 Feil, R., Brocard, J., Mascrez, B., LeMeur, M., Metzger, D., and Chambon, P. (1996) Ligandactivated site-specific recombination in mice. Proc. Natl. Acad. Sci. U S A 93, 10887-18890.

62 Weber, P., Metzger, D., and Chambon, P. (2001) Temporally controlled targeted somatic mutagenesis in the mouse brain. Eur. J. Neurosci. 14, 1777-1783.

63 Hayashi, S. and McMahon, AP. (2002) Efficient recombination in diverse tissues by a tamoxifen-inducible form of Cre: a tool for temporally regulated gene activation/inactivation in the mouse. Dev. Biol. 244, 305-318.

64 Holland, A. M., Hale, M. A., Kagami, H., Hammer, R. E., and MacDonald, R. J. (2002) Experimental control of pancreatic development and maintenance. Proc. Natl. Acad. Sci. US A 99, 12236-12241.

65 Sharma, A., Zangen, D. H., Reitz, P., Taneja, M., Lissauer, M. E., Miller, C. P., et al. (1999) The homeodomain protein IDX-1 increases after an early burst of proliferation during pancreatic regeneration. Diabetes 48, 507-513.

66 Ashery-Padan, R., Marquardt, T., Zhou, X., and Gruss, P. (2000) Pax6 activity in the lens primordium is required for lens formation and for correct placement of a single retina in the eye. Genes Dev. 14, 270-2711.

67 Ahlgren, U., Jonsson, J., and Edlund, H. (1996) The morphogenesis of the pancreatic mesenchyme is uncoupled from that of the pancreatic epithelium in IPF1/PDX1-deficient mice. Development 122, 1409-1416.

68 Harrison, K. A., Thaler, J., Pfaff, S. L., Gu, H., and Kehrl, J. H. (1999) Pancreas dorsal lobe agenesis and abnormal islets of Langerhans in Hlxb9-deficient mice. Nat. Genet. 23, 71-75.

69 Li, H., Arber, S., Jessell, T.M., and Edlund, H. (1999) Selective agenesis of the dorsal pancreas in mice lacking homeobox gene Hlxb9. Nat. Genet. 23, 67-70.

70 Naya, F. J., Huang, H. P., Qiu, Y., Mutoh, H., DeMayo, F. J., Leiter, A. B., et al. (1997) Diabetes, defective pancreatic morphogenesis, and abnormal enteroendocrine differentiation in BETA2/ neuroD-deficient mice. Genes Dev. 11, 2323-2334.

71 Clotman, F., Lannoy, V. J., Reber, M., Cereghini, S., Cassiman, D., Jacquemin, P., et al. (2002) The onecut transcription factor HNF6 is required for normal development of the biliary tract. Development 129, 1819-1828.

72 Sussel, L., Kalamaras, J., Hartigan-O'Connor, D. J., Meneses, J. J., Pedersen, R. A., Rubenstein, J. L., et al. (1998) Mice lacking the homeodomain transcription factor $\mathrm{Nkx2} .2$ have diabetes due to arrested differentiation of pancreatic beta cells. Development 125, 2213-2221.

73. Vogt, W. (1929) Gestaltungsanalyse am amphibienkeim mit örtlicher vitalfarbung. II. Teil. Gastrulation und mesodermbildung bei urodelen und anuran. Roux Arch. EntwMech. Org. 120, 384-706.

74. Vogt, W. (1924) Sitzungsber. Ges. Morph. Physiol München 35, 22-34.

75 Rosenquist, G. C. (1971) The location of the pregut endoderm in the chick embryo at the primitive streak stage as determined by radioautographic mapping. Dev. Biol. 26, 323-335.

76. Stern, C. D. and Canning, D. R. (1990) Origin of cells giving rise to mesoderm and endoderm in chick embryo. Nature 343, 273-275. 